\title{
Hypoxia counteracts taxol-induced apoptosis in MDA-MB-231 breast cancer cells: role of autophagy and JNK activation
}

\author{
A Notte $^{1}$, N Ninane ${ }^{1}$, T Arnould ${ }^{1}$ and C Michiels ${ }^{*, 1}$
}

Cancer cell resistance against chemotherapy is still a heavy burden to improve anticancer treatments. Autophagy activation and the development of hypoxic regions within the tumors are known to promote cancer cell resistance. Therefore, we sought to evaluate the role of autophagy and hypoxia on the taxol-induced apoptosis in MDA-MB-231 breast cancer cells. The results showed that taxol induced apoptosis after $16 \mathrm{~h}$ of incubation, and that hypoxia protected MDA-MB-231 cells from taxol-induced apoptosis. In parallel, taxol induced autophagy activation already after $2 \mathrm{~h}$ of incubation both under normoxia and hypoxia. Autophagy activation after taxol exposure was shown to be a protective mechanism against taxol-induced cell death both under normoxia and hypoxia. However, at longer incubation time, the autophagic process reached a saturation point under normoxia leading to cell death, whereas under hypoxia, autophagy flow still correctly took place allowing the cells to survive. Autophagy induction is induced after taxol exposure via mechanistic target of rapamycin (mTOR) inhibition, which is more important in cells exposed to hypoxia. Taxol also induced c-Jun N-terminal kinase (JNK) activation and phosphorylation of its substrates B-cell CLL/lymphoma $2\left(\mathrm{BCl}_{2}\right)$ and $\mathrm{BCL} 2$-like $1\left(\mathrm{Bcl}_{\mathrm{XL}}\right)$ under normoxia and hypoxia very early after taxol exposure. $\mathrm{BCl}_{2}$ and $\mathrm{Bcl}_{\mathrm{XL}}$ phosphorylation was decreased more importantly under hypoxia after long incubation time. The role of JNK in autophagy and apoptosis induction was studied using siRNAs. The results showed that JNK activation promotes resistance against taxolinduced apoptosis under normoxia and hypoxia without being involved in induction of autophagy. In conclusion, the resistance against taxol-induced cell death observed under hypoxia can be explained by a more effective autophagic flow activated via the classical mTOR pathway and by a mechanism involving $\mathrm{JNK}$, which could be dependent on $\mathrm{BCl}_{2}$ and $\mathrm{Bcl}_{\mathrm{XL}}$ phosphorylation but independent of JNK-induced autophagy activation.

Cell Death and Disease (2013) 4, e638; doi:10.1038/cddis.2013.167; published online 16 May 2013

Subject Category: Cancer

Accumulating evidence points to the fact that tumor microenvironment, which is very different from the one present in normal tissue, influences the pathophysiological characteristics of the tumor. A common feature of the environment associated in solid tumors is the presence of hypoxic areas within the tumor mass that develop when the high proliferation rate of tumor cells outstrips vasculature development. ${ }^{1}$ Tumor hypoxia is associated with a decrease in antitumor treatment efficacy such as radiation therapy and chemotherapy, and with a poor prognosis. ${ }^{2-4}$ More and more data showed that another process is also involved in the resistance against chemotherapy-induced cell death, which is autophagy. Autophagy is a highly conserved process during which parts of the cytoplasm including damaged, superfluous organelles or long-lived proteins are sequestered into double-membrane vesicles known as autophagosomes. These autophagosomes fused with lysosomes and their content is degraded by lysosomal proteases. This process allows energy supply during starvation through macromolecular building block recycling, defining autophagy as a protective mechanism. However, in cancer development, autophagy has been shown as having a dual role. ${ }^{5,6}$ In some cases, autophagy promotes tumorigenesis, but in others, autophagy is a tumor-suppressive mechanism. Therefore, one question that has emerged from recent studies is whether autophagy displays a cytotoxic or cytoprotective role. Experimental evidence coexists to support these two hypotheses. ${ }^{7-13}$ In parallel, the implication of autophagy in cell death processes was reevaluated, as a vast study testing 1400 compounds concluded that not a single antitumor compound turned out to kill tumor cells through the induction of autophagy. ${ }^{14}$ Recent reports also showed that hypoxia is able to modulate autophagy, leading to cell survival and resistance against anticancer therapies. ${ }^{15-19}$

This issue is even more complex as the molecular pathways regulating autophagy and apoptosis are interconnected. The modulation of one mechanism influences the execution of the

\footnotetext{
${ }^{1}$ Laboratory of Biochemistry and Cellular Biology, NARILIS, University of Namur-FUNDP, Namur, Belgium

${ }^{*}$ Corresponding author: C Michiels, Laboratory of Biochemistry and Cellular Biology, NARILIS, University of Namur, 61 rue de Bruxelles, 5000 Namur, Belgium. Tel: + 3281 724131; Fax: + 3281 724135; E-mail: carine.michiels@ unamur.be

Keywords: chemoresistance; breast cancer; hypoxia; apoptosis; autophagy; taxol

Abbreviations: Atg, autophagy related; $\mathrm{BCl}_{2}$, B-cell CLL/lymphoma 2; Bcl $\mathrm{XL}_{\mathrm{L}}, \mathrm{BCL2}$-like 1; Bnip3, BCL2/adenovirus E1B $19 \mathrm{kDa}$-interacting protein 3; BSA, bovine serum albumin; JNK, c-Jun N-terminal kinase; LAMP1, lysosomal-associated membrane protein 1; LC3, microtubule-associated protein 1 light chain 3 alpha; LDH, lactate dehydrogenase; mTOR, mechanistic target of rapamycin; p70S6K, ribosomal protein S6 kinase, $70 \mathrm{kDa}$, polypeptide 1; PARP, poly-(ADP-ribose) polymerase; RF, risc free

Received 05.12.12; revised 15.4.13; accepted 16.4.13; Edited by G Raschellà
} 
second one and vice-versa. ${ }^{20}$ Moreover, autophagic and apoptotic features can be observed in the very same cell, and both pathways share several key molecular regulators. ${ }^{21}$ One of them is beclin 1 , originally discovered as a B-cell CLL/lymphoma $2\left(\mathrm{Bcl}_{2}\right)$-interacting protein. ${ }^{22}$ Beclin 1 constitutively interacts with $\mathrm{Bcl}_{2}$ and $\mathrm{BCL}$-like $1\left(\mathrm{Bcl}_{X \mathrm{~L}}\right)$ in the endoplasmic reticulum. $\mathrm{BCl}_{2}$ and $\mathrm{BCl}_{X \mathrm{~L}}$ act as inhibitors of autophagy, as the binding of beclin 1 to them interferes with beclin 1/phosphatidylinositol 3-kinase VPS34 complex formation. Autophagy can be activated by different ways: in addition to the mechanistic target of rapamycin (mTOR) pathway, pro-apoptotic proteins such as Bcl2-associated agonist of cell death, BCL2-like 11 and BCL2/adenovirus E1B $19 \mathrm{kDa}$-interacting protein 3 (Bnip3) can interact with $\mathrm{BCl}_{2}$ and $\mathrm{Bcl}_{\mathrm{XL}}$ proteins, ${ }^{23}$ whereas the kinase c-Jun $\mathrm{N}$-terminal kinase (JNK) can phosphorylate $\mathrm{Bcl}_{2}$ and $\mathrm{Bcl}_{\mathrm{XL}}$, leading to $\mathrm{Bcl}_{2} / \mathrm{Bcl}_{\mathrm{XL}}$-beclin 1 complex disruption, beclin 1 release and subsequent autophagy activation. ${ }^{24,25}$. Nevertheless, we do not know how hypoxia and autophagy work together to modulate cancer cell response to chemotherapy-induced cell death. The aim of this study is to understand the implication of hypoxia and autophagy in the resistance of cancer cells against chemotherapy, and also to understand which mechanisms promote cell survival under hypoxia. For this purpose, human breast cancer MDA-MB231 cells were exposed to the chemotherapeutic agent paclitaxel (here refered as taxol); taxol being one of the most active agents used in the treatment of metastatic breast cancer. ${ }^{26}$

\section{Results}

Hypoxia protects MDA-MB-231 cells against taxol-induced apoptosis and cell death. Many studies have already shown that hypoxia influences drug-induced apoptosis differently according to the cancer cell lines ${ }^{27}$ and confers resistance against chemotherapy-induced apoptosis in numerous solid tumors. ${ }^{28-30}$ In order to study the effect of hypoxia on taxol-induced apoptosis, MDA-MB-231 cells were incubated under normoxia or hypoxia with or without taxol. It has to be noted that, in these conditions, hypoxia did lead to hypoxia-inducible factor- 1 activation and that taxol had very low influence on this process (Supplementary data 1). Caspase 3 and poly-(ADP-ribose) polymerase (PARP) cleavage was assessed after 2, 4, 816 and $24 \mathrm{~h}$ of incubation (Figure 1a) and caspase $3 / 7$ activity was measured after $16 \mathrm{~h}$ of incubation (Figure 1b). The effect of hypoxia on taxolinduced cell death was also studied by measuring cytotoxicity after $40 \mathrm{~h}$ (Figure 1c). No increase in caspase 3 activity, caspase 3 and PARP cleavage or in cytotoxicity was observed in cells exposed to hypoxia alone. Taxol did trigger apoptosis after $16 \mathrm{~h}$ of incubation as shown by an increase in caspase 3 and PARP cleavage, and in caspase 3 activity. In parallel, taxol induced a significant increase in cytotoxicity as shown by an increase in lactate dehydrogenase (LDH) release after $40 \mathrm{~h}$. Hypoxia inhibited the taxol-induced apoptosis and cell death as shown by a decrease in caspase 3 and PARP cleavage, as well as in caspase 3 activity and cytotoxicity. These data demonstrate that hypoxia is able to protect MDA-MB-231 cells against taxol-induced apoptosis and cell death.

Taxol activates autophagy and hypoxia modulates taxol-induced autophagy. Autophagy can be activated after exposure to hypoxia ${ }^{31}$ or to chemotherapeutic drugs ${ }^{12,32}$ including taxol. ${ }^{33}$ In order to evaluate the effect of hypoxia and/or taxol on autophagy, the abundance of microtubuleassociated protein 1 light chain 3 alpha (LC3) II and p62 was assessed by western blotting (Figure 2a). P62 is a protein known to be a selective substrate for degradation during autophagy. ${ }^{34}$ Taxol induced the conversion of LC3I to LC3II already after $4 \mathrm{~h}$ and the amount of LC3II increased with the incubation time. Hypoxia alone did not influence the taxolinduced LC3II conversion. After $4 \mathrm{~h}$, a decrease in p62 abundance was observed in cells incubated in the presence of taxol compared with control cells. This decrease in p62 abundance could correspond to early autophagic degradation. Unexpectedly, an increase in p62 abundance was observed after 16 and $24 \mathrm{~h}$ in cells incubated in the presence of taxol. This increase was lower in cells incubated under hypoxia. These results suggest that taxol induced early autophagy activation, which seems to be inhibited after 16 and $24 \mathrm{~h}$ under normoxia and to a lesser extent under hypoxia.

LC3 relocalization in the membranes of autophagic vacuoles and the fusion of autophagosomes with lysosomes was studied using immunofluorescence staining for LC3 as a marker for autophagosomes and lysosomal-associated membrane protein 1 (LAMP1) as a marker of lysosomes (Figure 2b). LC3I is a cytosolic protein that is recruited to the autophagosome membranes once autophagy is activated, giving a punctuate labeling. In control cells, we observed a diffuse LC3 labeling and a vacuole-like LAMP1 labeling. Taxol and to a lesser extent hypoxia alone induced an increase in LC3 punctuation and, in some cases, the LC3 labeling is associated to large vesicles that may correspond to swollen autophagosomes. Partial colocalization between LC3 and LAMP1 labeling was also observed after exposure to taxol under normoxia and hypoxia, meaning that the fusion between lysosomes and autophagosomes took place. Recent reports have shown that the microtubule network is important for autophagosome-lysosome fusion and for a correct degradation into autolysosomes. ${ }^{35-37}$ Autophagic degradation was then studied by monitoring lysosomal activity using the DQ-bovine serum albumin (BSA) fluorescent dye (Figure 2c). This dye is strongly selfquenched. Proteolysis of the BSA conjugates results in dequenching and release of protein fragments that contain isolated fluorophores, which are brightly fluorescent. In order to take into account only autophagy-dependent protease activity, DQ-Green-BSA proteolysis was also measured in the presence of bafilomycin $A$, an inhibitor of the vacuolar $\mathrm{H}+$-ATPase blocking the activity of the $\mathrm{pH}$-dependent lysosomal proteases. Results showed that autophagic degradation was clearly enhanced after exposure to taxol under normoxia and hypoxia. Moreover, DQ-BSA emission was detected in the lysosomes, as shown by colocalization with lysotracker red (Supplementary data 2). These results indicate that even if the microtubule network is disturbed, taxol exposure induced an increase in autophagic degradation under normoxia and hypoxia. 


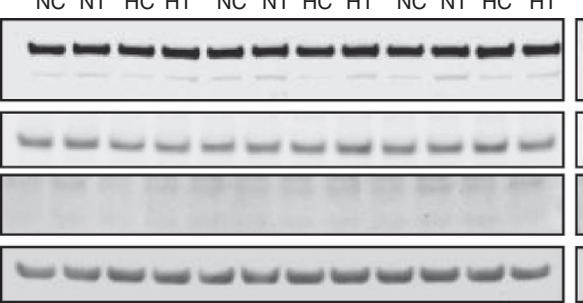

NC NT HC HT NC NT HC HT NC NT HC HT
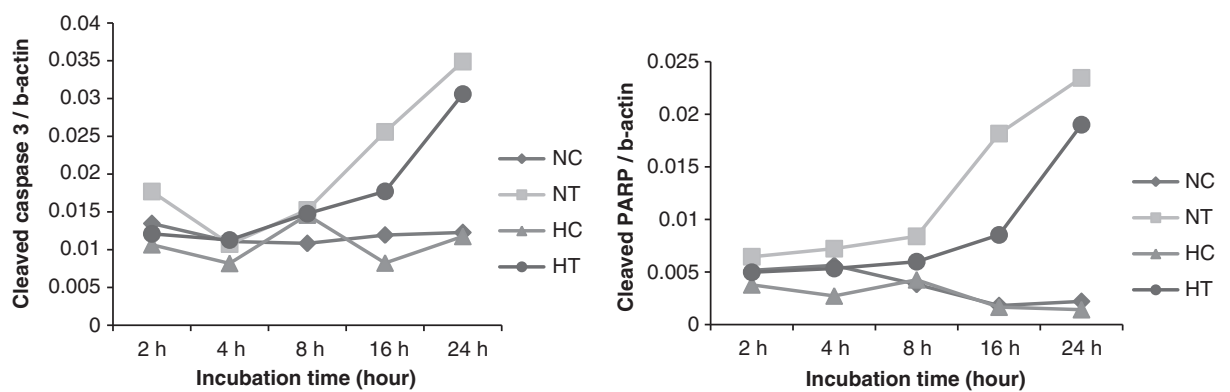

b
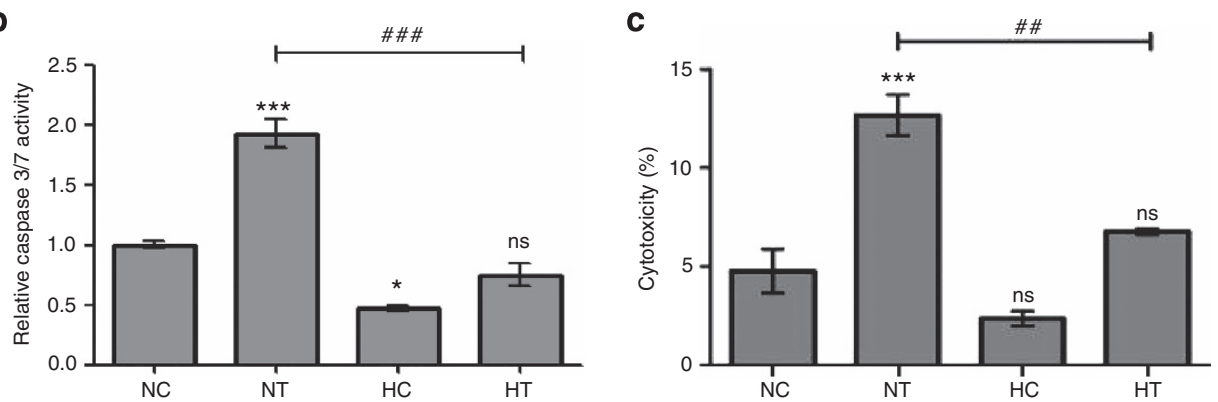

Figure 1 Hypoxia protects MDA-MB-231 cells against taxol-induced apoptosis and cell death. MDA-MB-231 cells were incubated under normoxia (N) or hypoxia (H) without (C) or with taxol (T) at $50 \mu \mathrm{M}$. (a) After 2, 4, 8, 16 and $24 \mathrm{~h}$ of incubation, cleaved caspase 3 and PARP-1 were detected in total cell extracts by western blotting analysis, using specific antibodies. $\beta$-actin was used to assess the total amount of proteins loaded on the gel. The graphs below represent the quantification of cleaved PARP and cleaved caspase 3 abundance normalized to the corresponding $\beta$-actin. (b) After $16 \mathrm{~h}$ of incubation, caspase 3 and 7 activity was assayed by measuring fluorescence intensity associated to free AFC released from the cleavage of caspase 3 and 7 substrate Ac-DEVD-AFC. Data are expressed in relative caspase 3/7 activity normalized to the control cells (NC) as means \pm 1 S.D. $(n=3)$. Statistical analysis was carried out with the one-way ANOVA test followed by a Bonferonni post test. NS: no significantly different

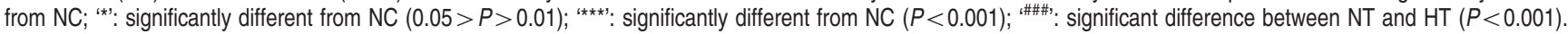
(c) After $40 \mathrm{~h}$ of incubation, LDH release was assayed. Results are expressed as means \pm 1 S.D. $(n=3)$. Statistical analysis was carried out with the one-way ANOVA test followed by a Bonferonni post test. NS: no significantly different from NC; '***': significantly different from NC $(P<0.001)$; "\#\#': significant difference between NT and HT $(0.01>P>0.001)$

Autophagy reaches a saturation point under normoxia after long incubation time. In order to explain the p62 accumulation observed after taxol treatment, p62 mRNA expression was assessed after 16 and $24 \mathrm{~h}$ (Supplementary data 3A). An increase in p62 mRNA expression was observed in cells exposed to taxol. This increase was lower in cells exposed to hypoxia. We investigated whether p62 accumulation observed at the protein level was due to transcriptional induction by incubating cells with actinomycin $D$ (Supplementary data $3 \mathrm{~B}$ and $\mathrm{C}$ ), a transcription inhibitor. Actinomycin D abrogated the taxol-induced p62 mRNA expression and $p 62$ protein accumulation, indicating that the increase in $p 62$ protein abundance resulted at least in part from an increase in p62 mRNA expression. In parallel, the autophagic flow was evaluated by measuring p62 protein abundance after the addition of bafilomycin $A$ or pepstatin $A+E 64 D$ during the incubation. PepstatinA and E64D inhibit lysosomal proteases. After incubation in the presence of these molecules, no increase in p62 protein abundance was observed in cells incubated with taxol under normoxia, whereas an increase in p62 protein abundance was observed in cells incubated with taxol under hypoxia (Supplementary data 4A and B). These results suggest that autophagy degradation reached a saturation point under normoxia and this was not the case under hypoxia. Moreover, addition of bafilomycin A resulted in an increase in p62 mRNA expression (Supplementary data $4 \mathrm{C}$ ), indicating that a disruption of the autophagic flow leads to induction of p62 expression. In conclusion, the increase in p62 abundance observed after taxol exposure could result from a perturbation in the autophagic flow. We suggest that in cells exposed to taxol under normoxia, autophagy is saturated after long incubation time leading to p62 accumulation and incorrect remediation of the stress induced by taxol. On the opposite, 
a
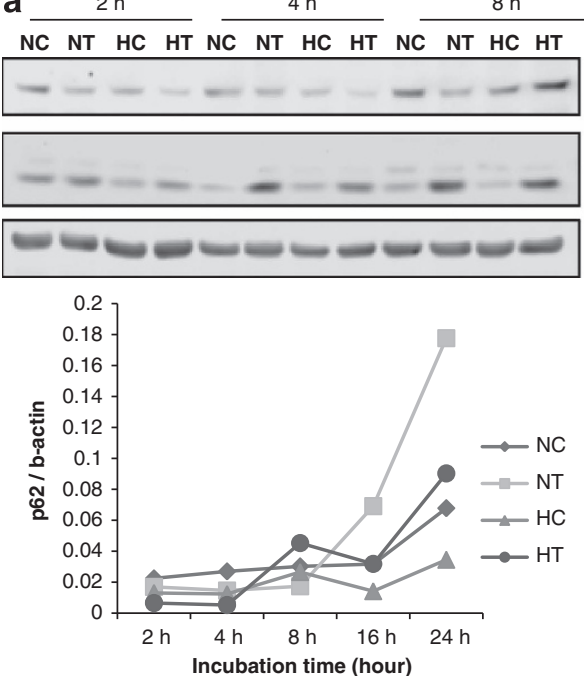

b

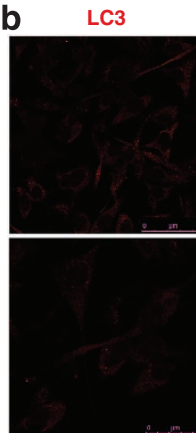

NC
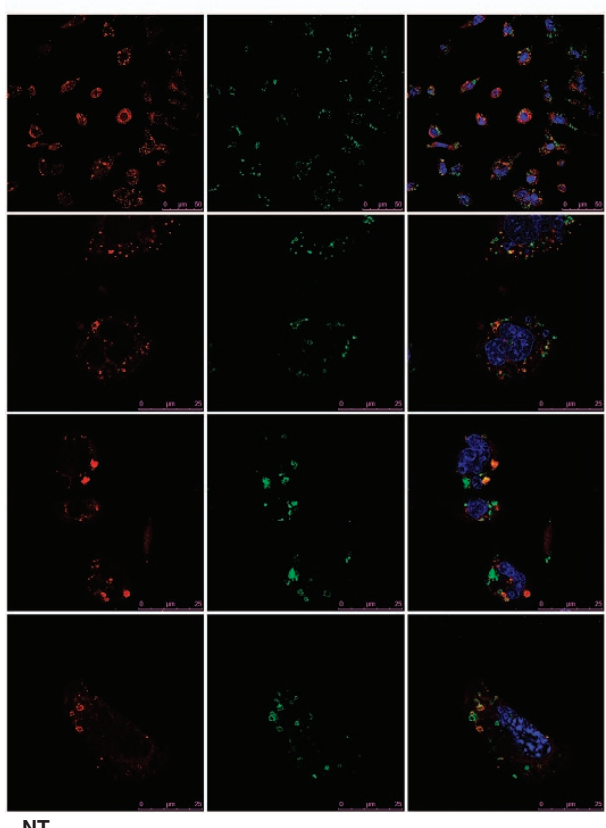

NT

Lamp1

merged
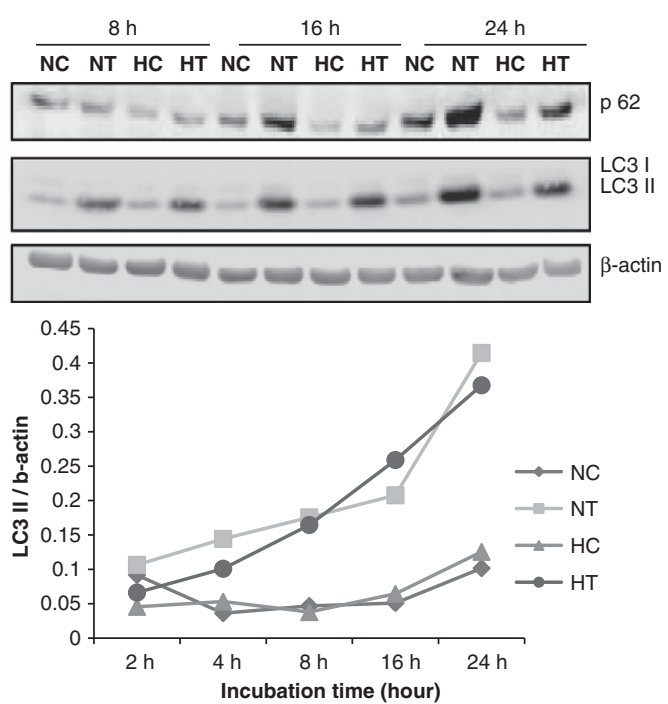

LC3

Lamp1

merged

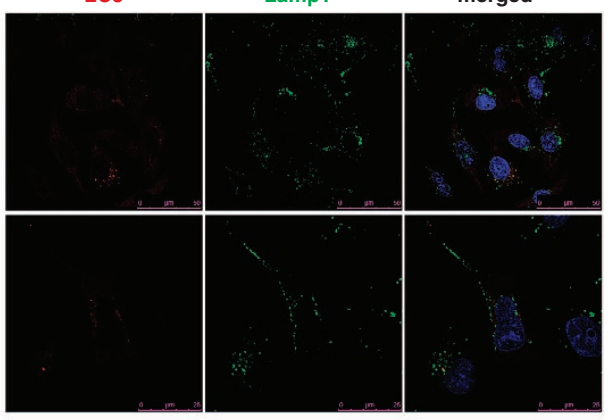

HC

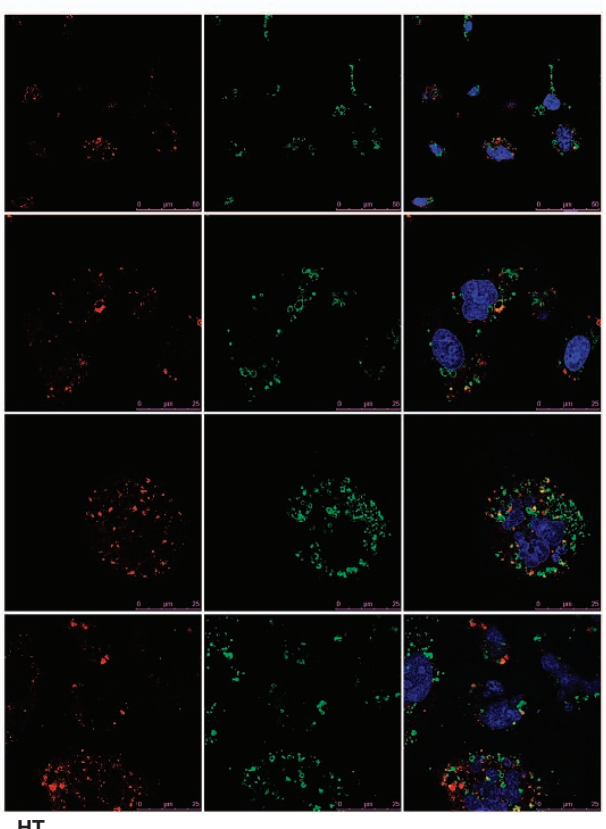

HT

Figure 2 Taxol induces LC3Il and p62 accumulation. MDA-MB-231 cells were incubated under normoxia (N) or hypoxia (H) without $(C)$ or with taxol $(T)$ at $50 \mu M$. (a) After $2,4,8,16$ and $24 \mathrm{~h}$ of incubation, LC3 and p62 were detected in total cell extracts by western blotting analysis, using specific antibodies. $\beta$-actin was used to assess the total amount of proteins loaded on the gel. The graphs below represent the quantification of the LC3II and p62 abundance normalized to the corresponding $\beta$-actin. (b) After $16 \mathrm{~h}$ of incubation, cells were fixed, permeabilized and stained for LC3 (red) and LAMP1 (green) using specific antibodies. Nuclei were detected with To-Pro-3 (blue). (c) After $16 \mathrm{~h}$ of incubation, lysosomal-dependent degradation was measured using DQ-Green-BSA dye. The histogram represents FL1 fluorescence intensity of unlabeled cells and cells incubated in the presence of DQ-Green-BSA under normoxia $(\mathrm{N})$ or hypoxia $(\mathrm{H})$ with $(\mathrm{T})$ or without $(\mathrm{C})$ taxol. The graph below represents the medians of fluorescence value for cells incubated under normoxia $(\mathrm{N})$ or hypoxia $(\mathrm{H})$ with $(\mathrm{T})$ or without $(\mathrm{C})$ taxol, without (grey columns) or with bafilomycin $\mathrm{A}$ (white columns) 

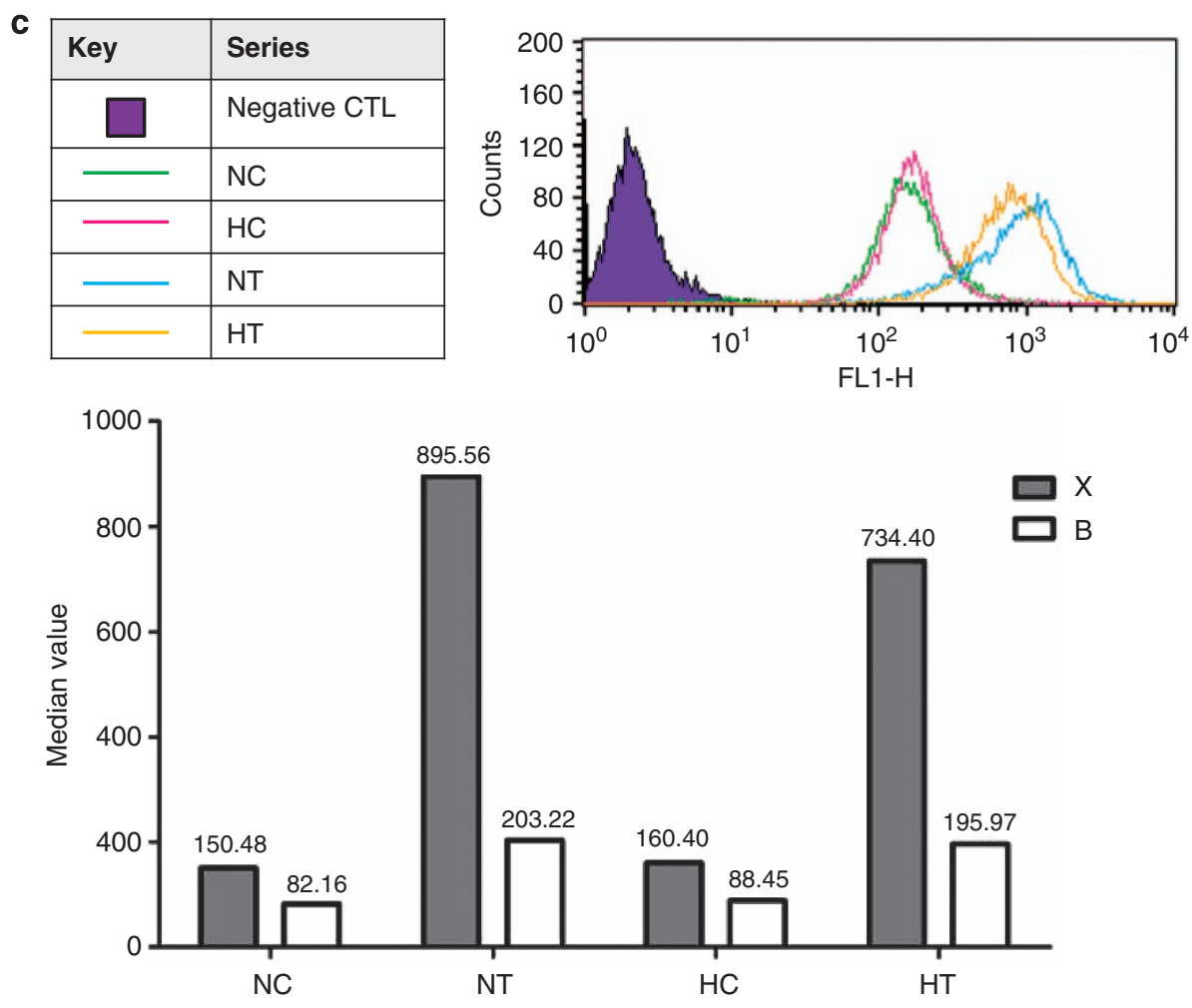

Figure 2 Continued.

cells exposed to taxol under hypoxia are still able to manage the stress, leading to less stressful conditions and to lower p62 accumulation.

As autophagy seemed to be differentially activated under normoxia and hypoxia, mTOR activity was studied to investigate the upstream signaling responsible for autophagy activation. The abundance of the phosphorylated forms of mTOR and p70S6K (ribosomal protein S6 kinase, $70 \mathrm{kDa}$, polypeptide 1; a target of $\mathrm{mTOR}$ ) was assessed (Figure 3). Taxol induced a decrease in p70S6K and mTOR phosphorylation already after $2 \mathrm{~h}$ and this decrease was time-dependent. Moreover, the taxol-induced decrease in p70S6K and mTOR phosphorylation was enhanced in cells incubated under hypoxia. These results confirm that the autophagic process was activated after taxol treatment and that hypoxia enhanced taxol-induced autophagy activation.

Finally, we analyzed if p62 accumulation represented a signaling event that could lead to cell death activation, as its accumulation was more important in cells exposed to taxol under normoxia. Cells were transfected with p62 siRNAs or risc-free (RF) siRNA, used as a negative control. P62 protein level was markedly reduced in p62 siRNA-transfected cells, but its invalidation influenced neither autophagy induction nor taxol-induced apoptosis and cell death (Supplementary data 5).

Autophagy promotes resistance against taxol-induced cell death in a Bnip3 independent way. As autophagy can promote cell survival, we sought to determine the role of taxol-induced autophagy in the modulation of cell death. For this purpose, autophagy was inhibited using autophagy related (Atg) 7 and Atg5 siRNA. Atg7 is the E2 enzyme required for the ubiquitin-like conjugation of Atg5 to Atg12 at the early step of autophagy activation. Cells were transfected with either Atg7 or Atg5 siRNA, or RF siRNA, used as a negative control, and incubated under normoxia or hypoxia with or without taxol. Atg7 protein level was markedly reduced in Atg7 siRNA-transfected cells (Figure 4a). Atg7 invalidation prevented autophagy induction by taxol as shown by a decrease in taxolinduced conversion of LC3I to LC3II. On the other hand, Atg7 enhanced taxol-induced caspase 3 and PARP cleavage under normoxia and hypoxia. Silencing of Atg7 also increased caspase 3/7 activity (Figure $4 b$ ). Similar results were obtained after Atg5 invalidation with siRNAs (Supplementary data 6). These results suggest that autophagy inhibition resulted in enhanced apoptosis.

In order to confirm the protective role of autophagy against taxol-induced cell death, cells were incubated with rapamycin, which inhibits the kinase mTOR and leads to autophagy activation. Rapamycin led to a decrease in taxol-induced LDH release under normoxia, to a lesser extent under hypoxia (Figure 4d), and to a decrease in caspase 3 cleavage (Figure 4c), suggesting that autophagy activation prevented cell death. Altogether, these results indicate that autophagy promotes resistance against taxol-induced cell death.

As BNIP3 has been shown to be involved in the induction of pro-survival autophagy under hypoxia, ${ }^{16,38}$ we studied whether BNIP3 and/or BNIP3L were involved in the regulation of autophagy. Results showed that neither taxol, nor hypoxia modified BNIP3L abundance. The role of this protein was thus 


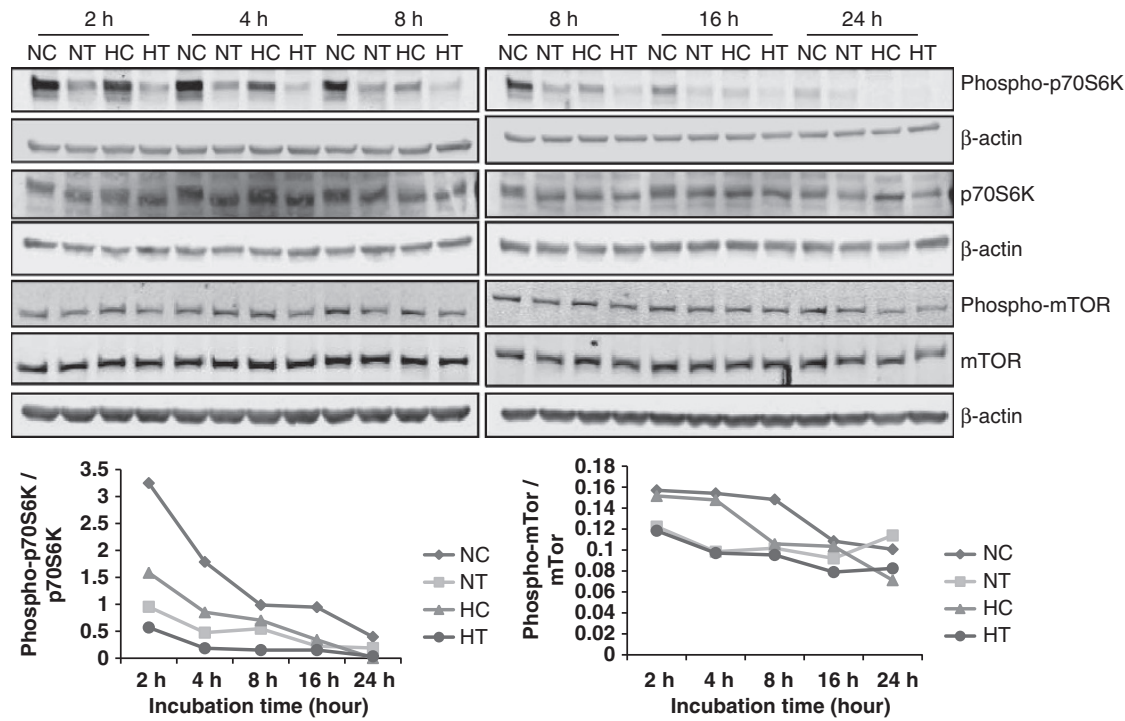

Figure 3 Hypoxia modulates taxol-induced autophagy. MDA-MB-231 cells were incubated under normoxia $(\mathrm{N})$ or hypoxia $(\mathrm{H})$ without $(\mathrm{C})$ or with taxol $(\mathrm{T})$ at $50 \mu \mathrm{M}$. (a) After 2, 4, 8, 16 and $24 \mathrm{~h}$ of incubation, (phospho)-p70S6K and (phospho)-mTOR were detected in total cell extracts by western blotting analysis, using specific antibodies. $\beta$-actin was used to assess the total amount of proteins loaded on the gel. The graphs below represent the quantification of phospho-p70S6K and phospho-mTOR abundance normalized to $\beta$-actin relative to $\mathrm{p} 70 \mathrm{~S} 6 \mathrm{~K}$ and $\mathrm{mTOR}$ total abundance normalized to $\beta$-actin

not investigated further. On the other hand, BNIP3 abundance markedly increased in the mitochondria containing fraction of cells incubated under hypoxia for $24 \mathrm{~h}$. The abundance was even more increased in the presence of taxol (Supplementary data 7). The role of BNIP3 was then investigated. Results showed that BNIP3 silencing using siRNA had no clear cut effect on apoptosis in cells incubated with taxol under hypoxia (Supplementary data 8).

Taxol induces JNK activation and JNK-dependent $\mathrm{BCl}_{2}$ and $\mathrm{BCl}_{\mathrm{XL}}$ phosphorylation. Various reports showed that taxol induces JNK activation. ${ }^{39-41}$ In order to investigate whether taxol induced JNK activation and $\mathrm{BCl}_{2} / \mathrm{Bcl}_{\mathrm{XL}}$ phosphorylation, the abundance of $\mathrm{c}-\mathrm{jun}, \mathrm{Bcl}_{2}, \mathrm{Bcl}_{\mathrm{XL}}$ and the phosphorylated forms of these proteins was assessed by western blotting using specific antibodies raised against JNK phosphorylation sites (Figure 5a). Taxol induced c-jun, $\mathrm{Bcl}_{2}$ and $\mathrm{BCl}_{\mathrm{XL}}$ phosphorylation at early time point under normoxia and hypoxia, whereas a decrease in the abundance of these phosphorylation forms was observed after 16 and $24 \mathrm{~h}$ under hypoxia. JNK invalidation with siRNAs showed that $\mathrm{Bcl}_{2}$ and $\mathrm{Bcl}_{\mathrm{XL}}$ phosphorylation was JNK-dependent, as JNK invalidation (Supplementary data 9) resulted in a decrease in phospho-Bcl 2 and phospho-Bcl $\left.\right|_{\mathrm{XL}}$ abundance (Figure $5 \mathrm{~b}$ ).

JNK promotes cell survival without being involved in autophagy induction. As recent reports showed that JNKdependent phosphorylation of $\mathrm{BCl}_{2}$ and $\mathrm{Bcl}_{X \mathrm{~L}}$ can lead to cell death and/or autophagy activation, ${ }^{24,42,43}$ the implication of JNK in taxol-induced apoptosis and autophagy was investigated after JNK silencing. Results showed that JNK inhibition increased taxol-induced caspase 3 and PARP cleavage, as well as caspase $3 / 7$ activity and cytotoxicity under normoxia and hypoxia. These data suggest that JNK activation promoted cell survival after taxol exposure under normoxia and hypoxia (Figure 6a-c).

The role of JNK activation in autophagy regulation was then studied. JNK silencing resulted in a small increase in LC3II abundance in cells incubated in the presence of taxol, as well as to a decrease in $p 62$ abundance only in cells incubated with taxol under normoxia (Figure 7a). In addition, results showed that JNK does not regulate autophagy induction, as no modification in the fluorescence value corresponding to DQ-BSA proteolysis was observed in cells transfected with the JNK siRNA compared with untransfected cells when cells were incubated with taxol (Figure 7b).

Neither Beclin 1 nor ATG5 cleavage is involved in autophagy inhibition. It is reported that Beclin 1 and ATG5 are cleaved during apoptosis and that this cleavage can lead to autophagy inhibition or to apoptosis induction, respectively. ${ }^{44,45}$ Supplementary data 10 shows that neither taxol nor hypoxia induced calpain-mediated Atg5 cleavage whatever the duration of the incubation. On the other hand, western blot analysis showed that a cleaved fragment of Beclin 1 appeared at an apparent molecular weight of about $41 \mathrm{kDa}$ after $16 \mathrm{~h}$ of incubation (Supplementary data 11 ). In order to investigate whether this cleavage is a consequence of apoptosis induction, cells were incubated in the presence of Z-VAD-fmk, a pan-caspase inhibitor. Results showed that caspase inhibition prevented the apparition of the cleaved fragment in cells incubated with taxol, indicating that it is probably a consequence of apoptosis activation rather than an event that participates to apoptosis induction (Supplementary data 12). As the molecular weight of the cleaved fragment was not the expected one, in silico analysis using the SitePrediction website ${ }^{46}$ of the beclin 1 protein sequence revealed several classical caspase recognition 
a

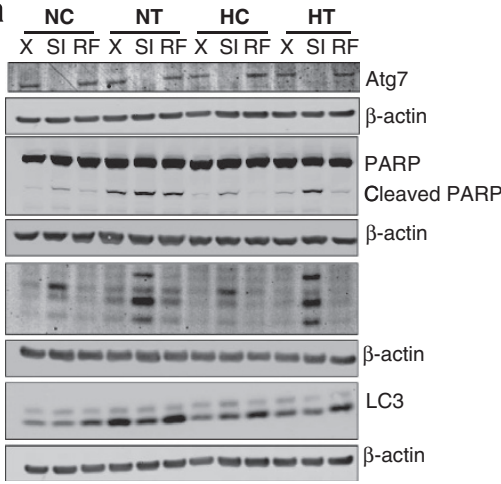

C

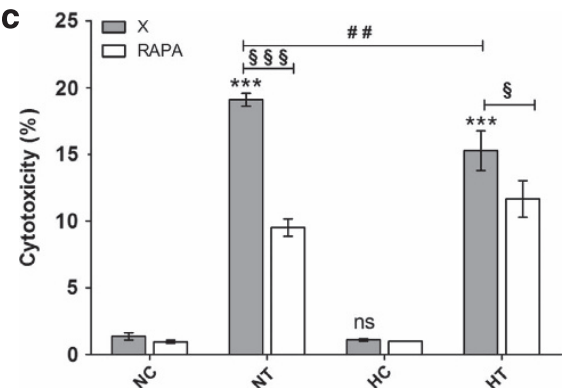

b

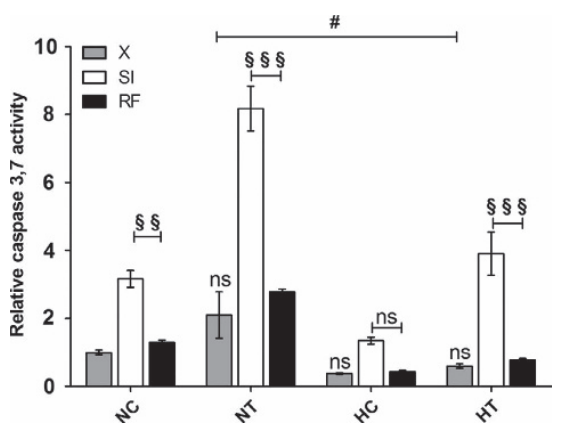

d

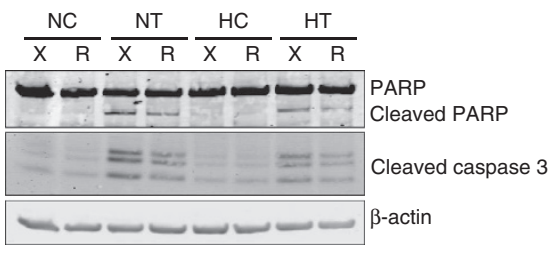

Figure 4 Autophagy promotes cell survival after taxol incubation under normoxia and hypoxia. (a and $\mathbf{b})$ MDA-MB-231 cells were untransfected (X) or transfected with Atg7 siRNA (SI) or negative control RF siRNA (RF) at $50 \mathrm{nM}$ for $24 \mathrm{~h}$. The transfection media were removed and replaced by culture media for $24 \mathrm{~h}$. Cells were then incubated under normoxia (N) or hypoxia $(\mathrm{H})$ for $16 \mathrm{~h}$, without $(\mathrm{C})$ or with taxol $(\mathrm{T})$ at $50 \mu \mathrm{M}$. (a) Atg7, PARP, cleaved PARP, cleaved caspase 3 and LC3 were detected in total cell extracts by western blotting analysis, using specific antibodies. $\beta$-actin was used to assess the total amount of proteins loaded on the gel. (b) Caspase 3 and 7 activity was assayed by measuring fluorescence intensity associated to free AFC released from the cleavage of caspase 3 and 7 substrate Ac-DEVD-AFC. Results are expressed in relative caspase $3 / 7$ activity normalized by fluorescence intensity of the control cells (NCX) and presented as means \pm 1 S.D. ( $n=3$ ). Statistical analysis was carried out with the two-way ANOVA test followed by a Bonferonni post test. NS: no significantly different from NC X; "\#': significant difference between NT X and HT X $(0.05>P>0.01)$; NS: no significant difference between HC SI and HC RF; ‘\$\$; significant difference between NC SI and NC RF (NC $0.01>P>0.001)$; ' $\$ \S \S$; significant difference between NT SI and NT RF, HT SI and HT RF $(P<0.001)$. (c and d) MDA-MB-231 cells were incubated under normoxia (N) or hypoxia $(\mathrm{H})$, without $(\mathrm{C})$ or with taxol $(\mathrm{T})$ at $50 \mu \mathrm{M}$ combined or not $(\mathrm{X})$ with rapamycin (autophagy activator) at $100 \mathrm{nM}$ (RAPA). (c) After $16 \mathrm{~h}$ of incubation, cleaved caspase 3 was detected in total cell extracts by western blotting analysis, using specific antibodies. $\beta$-actin was used to assess the total amount of proteins loaded on the gel. (d) After $40 \mathrm{~h}$ of incubation, LDH release was assessed. Results are expressed in percentage of viability as means \pm 1 S.D. $(n=3)$. Statistical analysis was carried out with the two-way ANOVA test followed by a Bonferonni post test. NS: no

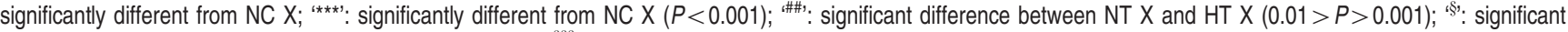
difference between HT $X$ and HT RAPA $(0.05>P>0.01)$; ‘\$\$; significant difference between NT $X$ and NT RAPA $(P<0.001)$

sites: of these, cleavage by caspase 3/7 after EASD105 would generate fragment of $40.3 \mathrm{kDa}$ (Supplementary data 13 ). Finally, we investigated whether beclin 1 cleavage by caspases after long incubation time would be a negative feedback mechanism leading to autophagy inhibition. Results showed that LC3II and p62 abundance as well as autophagic degradation remained unchanged in cells incubated with Z-VAD-fmk compared with cells incubated without the caspase inhibitor (Supplementary data 14). These results showed that caspase-mediated cleavage of beclin 1 did not have a role in autophagy inhibition.

\section{Discussion}

One largely studied factor promoting cancer cell resistance against radiotherapy and chemotherapy is the development of hypoxic regions within the tumor mass and subsequent hypoxia-inducible factor-1 activation. In addition to hypoxia, another process having a role in cancer resistance has been highlighted in these past years, which is autophagy. Although basal autophagy occurs in most cells, this process is also activated by various stresses such as nutrient depletion, hypoxia or chemotherapeutic treatment. ${ }^{12,47}$ Therefore, we sought to evaluate the role of autophagy and hypoxia in the taxol-induced apoptosis. Apoptosis was activated after $16 \mathrm{~h}$ of incubation in the presence of taxol and hypoxia conferred resistance against taxol-induced cell death. Autophagy was also activated after taxol exposure, much earlier than apoptosis. It should be noted that conflicting reports exist about the effects of mitotic/microtubule inhibitors on autophagy. Early studies interpreted increased number of autophagosomes as evidence of autophagy induction, whereas other studies as evidence of autophagic flow inhibition. ${ }^{35,37,48-50}$ Therefore, autophagy kinetics was studied. Results showed that taxol exposure led to autophagy induction as shown by an increase in LC3II abundance, early decrease in p62 abundance, mTOR inhibition and increase in autophagic degradation. At longer incubation time, p62 accumulation observed in cells incubated in the presence of taxol suggested that autophagy capacity was saturated. This 


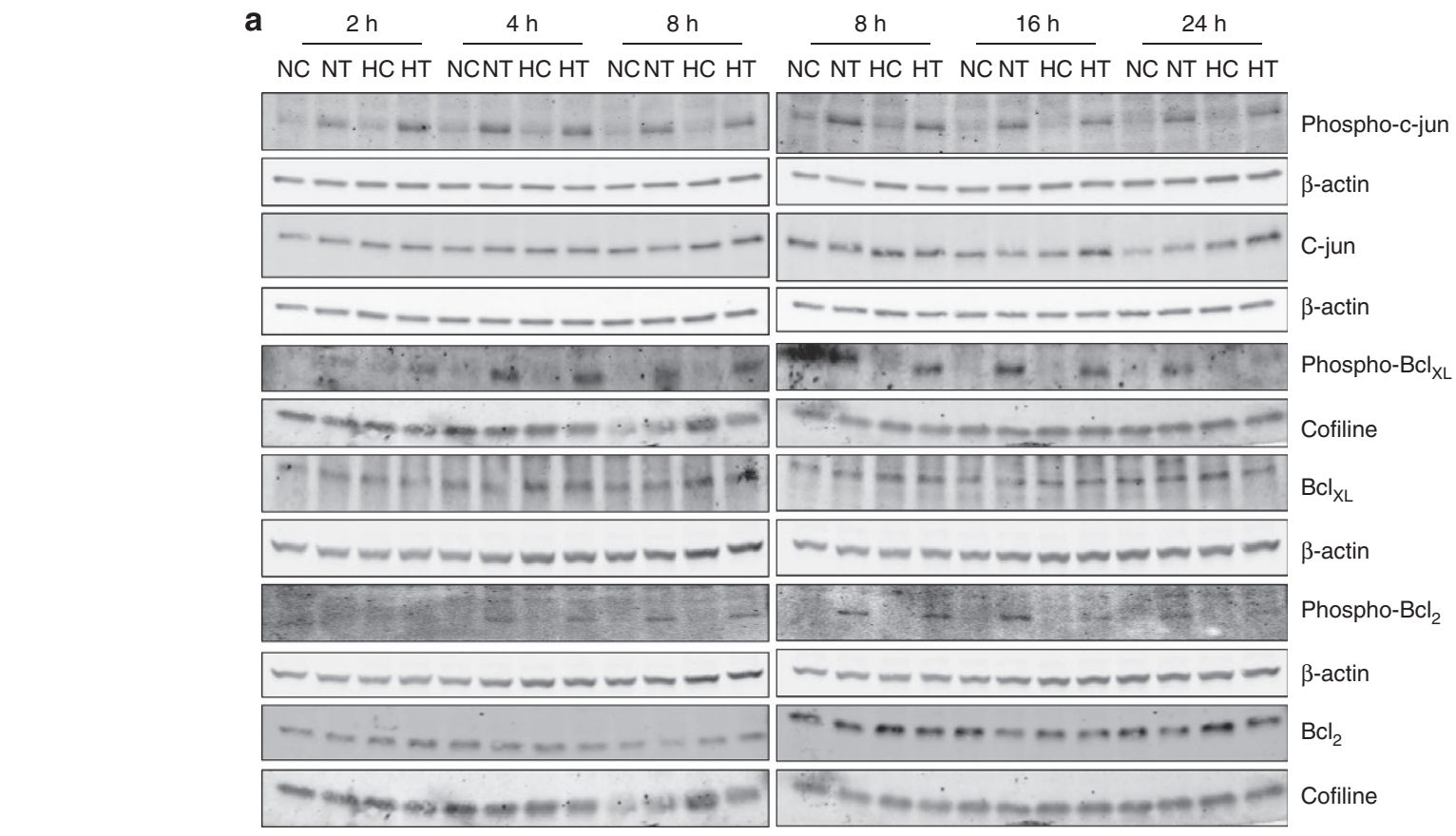

$8 \mathrm{~h} \quad 16 \mathrm{~h} \quad 24 \mathrm{~h}$

NC NT HC HT NCNT HC HT NC NT HC HT
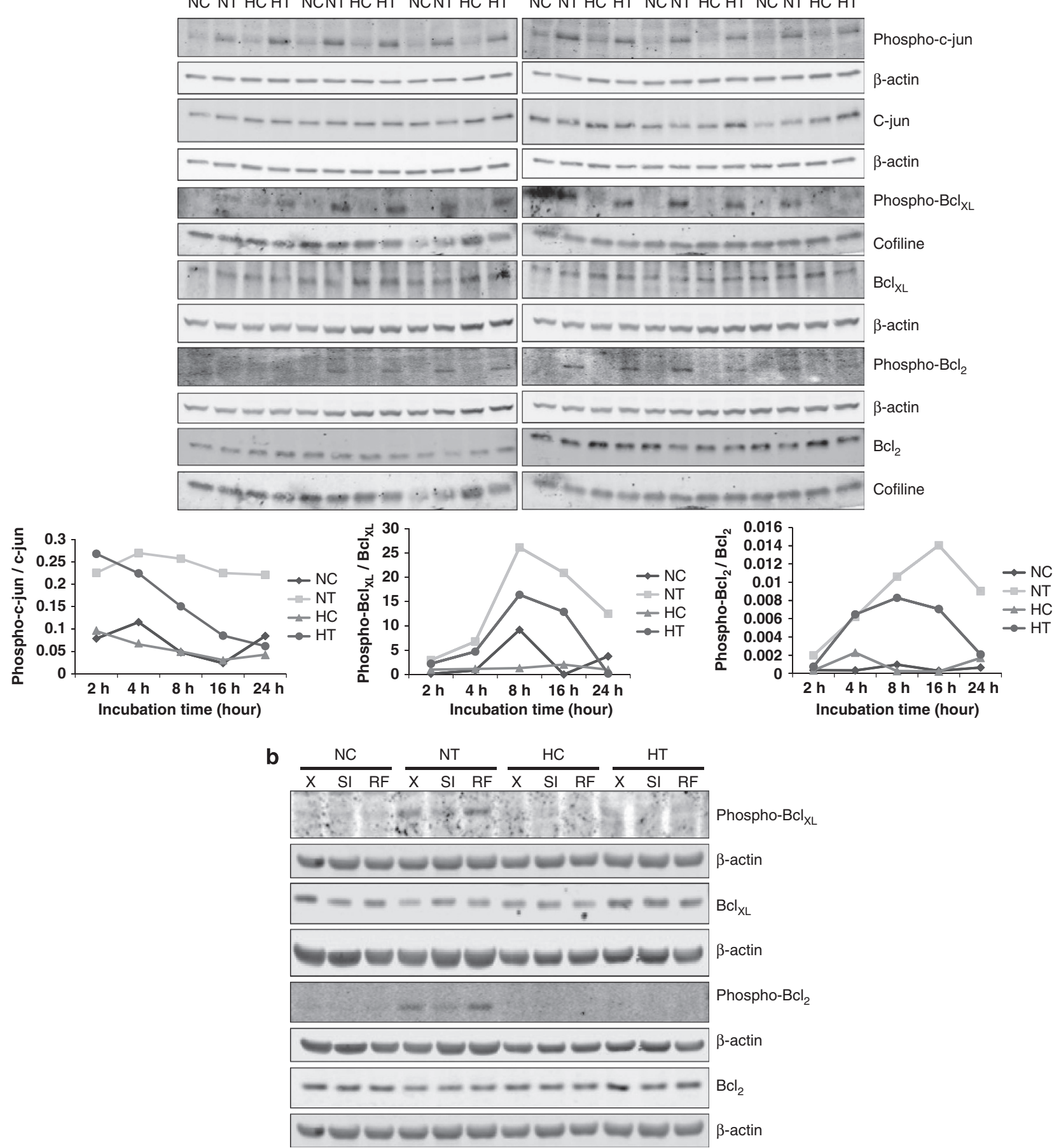

Figure 5 JNK-dependent phosphorylation of $\mathrm{c}$-jun, $\mathrm{Bc}_{2}$ and $\mathrm{Bc}_{\mathrm{XL}}$ is induced by taxol but decreased after long incubation time under hypoxia. MDA-MB-231 cells were incubated under normoxia (N) or hypoxia (H) without (C) or with taxol (T) at $50 \mu \mathrm{M}$. (a) After 2, 4, 8, 16 and $24 \mathrm{~h}$ of incubation, c-jun, Bcl $2, \mathrm{Bcl}_{x \mathrm{~L}}$, phospho-c-jun, phospho-Bcl 2 and phospho-Bcl $x_{\mathrm{L}}$ were detected in total cell extracts, obtained with a phospho-protein-specific lysis buffer, by western blotting analysis, using specific antibodies. $\beta$-actin was used to assess the total amount of proteins loaded on the gel. The graphs below represent the quantification of phospho-c-jun, phospho-Bcl 2 and phospho-Bcl $\mathrm{BL}_{\mathrm{L}}$ abundance normalized to $\beta$-actin relative to $\mathrm{c}$-jun, $\mathrm{Bcl}_{2}$ and $\mathrm{Bc}_{\mathrm{XL}}$ total abundance normalized to $\beta$-actin. (b) MDA-MB-231 cells were untransfected (X) or transfected with $25 \mathrm{nM}$ of JNK1 and $25 \mathrm{nM}$ of JNK2 siRNA (SI) or negative control RF siRNA at $50 \mathrm{nM}(\mathrm{RF})$ for $24 \mathrm{~h}$. The transfection media were removed and replaced by culture media for $24 \mathrm{~h}$. Cells were then incubated under normoxia $(\mathrm{N})$ or hypoxia $(\mathrm{H})$ for $16 \mathrm{~h}$, without $(\mathrm{C})$ or with taxol $(\mathrm{T})$ at $50 \mu \mathrm{M}$. Bcl, $\mathrm{Bcl}_{\mathrm{XL}}$, phospho-Bcl $\mathrm{L}_{2}$, phospho-Bcl $\mathrm{xL}_{\mathrm{L}}$ were detected in total cell extracts, obtained with a phospho-protein-specific lysis buffer, by western blotting analysis, using specific antibodies. $\beta$-actin was used to assess the total amount of proteins loaded on the gel 
a

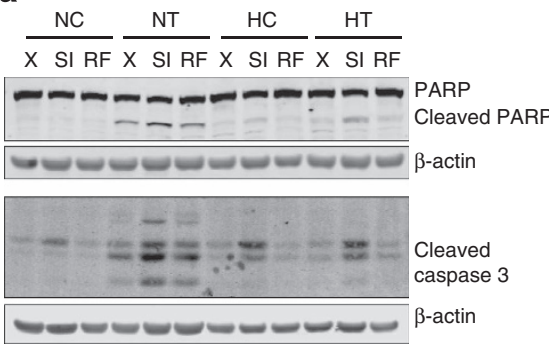

$\mathbf{b}_{6}$

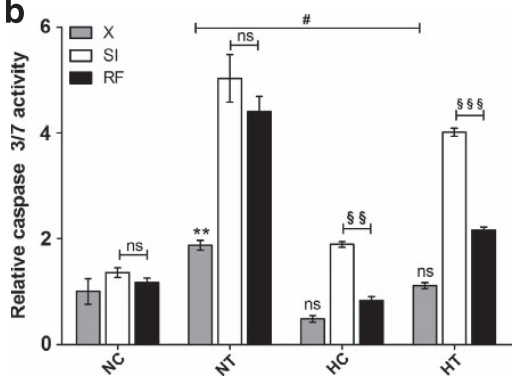

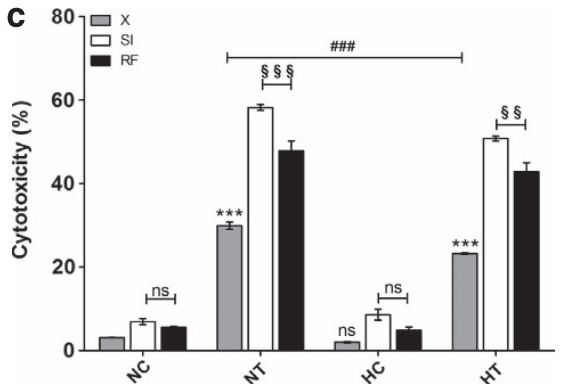

Figure 6 JNK promotes cell survival against taxol-induced cell death. MDA-MB-231 cells were untransfected $(\mathrm{X})$ or transfected with $25 \mathrm{nM}$ of JNK1 and $25 \mathrm{nM}$ of JNK2 siRNA (SI) or negative control RF siRNA at $50 \mathrm{nM}(\mathrm{RF})$ for $24 \mathrm{~h}$. The transfection media were removed and replaced by culture media for $24 \mathrm{~h}$. Cells were then incubated under normoxia ( $\mathrm{N}$ ) or hypoxia $(\mathrm{H})$ for $16 \mathrm{~h}$, without $(\mathrm{C})$ or with taxol $(\mathrm{T})$ at $50 \mu \mathrm{M}$. (a) After $16 \mathrm{~h}$ of incubation, PARP, cleaved PARP and cleaved caspase 3 were detected in total cell extracts by western blotting analysis, using specific antibodies. $\beta$-actin was used to assess the total amount of proteins loaded on the gel. (b) After $16 \mathrm{~h}$ of incubation, caspase 3 and 7 activity was assayed by measuring fluorescence intensity associated to free AFC released from the cleavage of caspase 3 and 7 substrate Ac-DEVD-AFC. Results are expressed in relative caspase $3 / 7$ activity normalized by fluorescence intensity of the control cells (NC) and presented as means \pm 1 S.D. $(n=3)$. Statistical analysis was carried out with the two-way ANOVA test followed by a Bonferonni post test. NS: no significantly different from corresponding NC; “**: significantly different from NC $X$ $(0.01>P>0.001)$; "\#': significant difference between NT X and HT X $(0.05>P>0.01)$; NS: no significant difference between NC SI and NC RF and between NT SI and NT RF; "s\$; significant difference between HC SI and HC RF $(0.01>P>0.001)$; $\$ \$ \$$ ' significant difference between HT SI and HT RF $(0.01>P>0.001)$. (c) After $40 \mathrm{~h}$ of incubation, LDH release was assayed. Results are expressed as means \pm 1 S.D. $(n=3)$. Statistical analysis was carried out with the two-way ANOVA test followed by a Bonferonni post test. NS: no significantly different from NC X; ‘***': significantly different from NC X $(P<0.001)$; “\#\#”; : significant difference between NT X and HT $X$

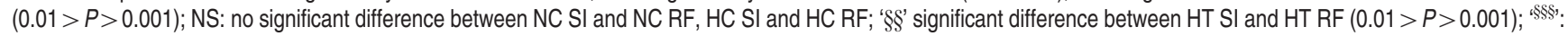
significant difference between NT SI and NT RF $(P<0.001)$
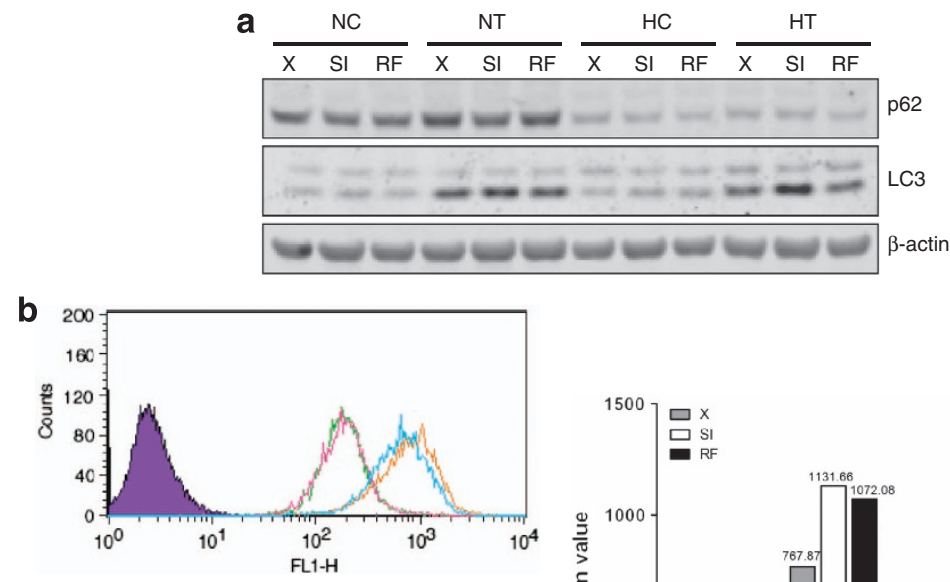

\begin{tabular}{|c|l|}
\hline Key & Series \\
\hline$\square$ & Negative CTL \\
\hline & NC \\
\hline & HC \\
\hline & NT \\
\hline & HT \\
\hline
\end{tabular}

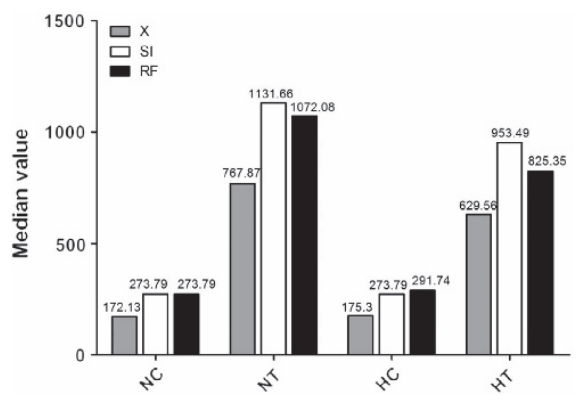

Figure 7 JNK is not involved in taxol-induced autophagy activation. MDA-MB-231 cells were untransfected $(\mathrm{X})$ or transfected with $25 \mathrm{nM}$ of JNK1 and $25 \mathrm{nM}$ of JNK2 siRNA (SI) or negative control RF siRNA at $50 \mathrm{nM}$ (RF) for $24 \mathrm{~h}$. The transfection media were removed and replaced by culture media for $24 \mathrm{~h}$. Cells were then incubated under normoxia (N) or hypoxia $(\mathrm{H})$ for $16 \mathrm{~h}$, without $(\mathrm{C})$ or with taxol $(\mathrm{T})$ at $50 \mu \mathrm{M}$. (a) LC3 and p62 were detected in total cell extracts, obtained with a phospho-protein-specific lysis buffer, by western blotting analysis, using specific antibodies. $\beta$-actin was used to assess the total amount of proteins loaded on the gel. (b) Cells were incubated in the presence of the DQ-Green-BSA fluorescent dye (unlabeled cells serve as a negative control). After incubation, cells were harvested and analyzed by flow cytometry

overloading was more important in cells incubated under normoxia, resulting in stress persistence and apoptosis activation. On the other hand, in cells incubated with taxol under hypoxia, the autophagic flow was enhanced (as shown by a more important mTOR inhibition), leading to more efficient autophagic process, stress solving and no apoptosis activation. Recently, Veldhoen et al. ${ }^{48}$ showed that taxol inhibits autophagy in MCF-7 and SKBR3 cells, suggesting that taxol inhibits basal autophagy rather than inducing it. This inhibition was explained by the fact that taxol disturbs the 
microtubule network and autophagosome movement. Another study showed that disruption of microtubules with taxol led to a reduction in the number of mature autophagosomes but did not affect their lifespan or their fusion with lysosomes. ${ }^{35} \mathrm{~A}$ point in common between our work and Veldhoen et al. ${ }^{48}$ study is that autophagy saturation is a signaling event, leading to apoptosis activation, but the mechanisms involved are not known. On the other hand, the discrepancies regarding the effect of taxol on autophagy induction could also be explained by the fact that the concentration of taxol and the cell lines used were different. Moreover, Veldhoen et al. ${ }^{48}$ did not measure autophagic degradation quantitatively and did not study autophagy kinetics at early time point. Regarding the effect of hypoxia, similar observations as the once described here have been made in previous studies, showing that hypoxia accelerates the autophagic clearance of p62 protein and that an increase in the turnover of acidic vesicles results in chemotherapy resistance. ${ }^{51,52}$ We also showed that autophagy activation promotes cell survival after taxol exposure, as Atg7 or Atg5 silencing resulted in a decrease in taxol-induced autophagy and enhanced the taxol-induced apoptosis activation under normoxia and hypoxia. This was confirmed by the fact that activation of autophagy by rapamycin resulted in a decrease in taxol-induced apoptosis and cell death.

In conclusion, apoptosis and autophagy are activated in MDA-MB-231 cells after taxol exposure. Autophagy is activated before apoptosis, suggesting that autophagy is first activated as a protective mechanism followed by apoptosis activation at longer time when the stress is not relieved. Different mechanisms are known to regulate the switch between autophagy and apoptosis. One of them involves the activation of the JNK kinase and phosphorylation of two members of the $\mathrm{Bcl}_{2}$ family: $\mathrm{Bcl}_{2}$ and $\mathrm{BCl}_{\mathrm{XL}} .{ }^{24}$ Phosphorylation of $\mathrm{BCl}_{2}$ and $\mathrm{BCl}_{\mathrm{XL}}$ located at the endoplasmic reticulum results in autophagy induction, whereas apoptosis regulation is restricted to $\mathrm{BCl}_{2}$ and $\mathrm{Bcl}_{\mathrm{XL}}$ located at the mitochondria. ${ }^{53}$ Another hypothesis proposes that activation of autophagy or apoptosis is determined by the stress intensity. Indeed, Wei et al. ${ }^{24}$ showed that after cell starvation, the association between beclin 1 and $\mathrm{BCl}_{2}$ is disrupted, due to JNK1-mediated $\mathrm{BCl}_{2}$ phosphorylation, thus promoting autophagy while phosphorylated $\mathrm{Bcl}_{2}$ is still able to interact with the pro-apoptotic protein Bax inhibiting apoptosis. However, under extreme conditions, JNK1 mediates hyper-phosphorylation of $\mathrm{Bcl}_{2}$, which detaches from Bax, thus facilitating apoptosis and consequently cell death. Moreover, studies describe a dual role for the JNK kinase in apoptosis regulation. ${ }^{54}$ In some reports, taxol-induced $\mathrm{JNK}$ activation and $\mathrm{BCl}_{2}$ phosphorylation led to cell death, whereas in other reports, JNK activation resulted in cell survival. ${ }^{40,55-57}$ Furthermore, Ventura et al. ${ }^{58}$ showed that after TNF $\alpha$ stimulation, early JNK activation promoted survival, whereas prolonged activation of JNK led to cell death. Here, we showed that taxol induced JNKdependent phosphorylation of $\mathrm{BCl}_{2}$ and $\mathrm{BCl}_{\mathrm{XL}}$ very rapidly under normoxia and hypoxia, and that the abundance of the phosphorylated forms of $\mathrm{BCl}_{2}$ and $\mathrm{BCl}_{\mathrm{XL}}$ was decreased after longer incubation time under hypoxia. In parallel, JNK invalidation led to an increase in apoptosis and cell death under normoxia and hypoxia, suggesting that taxol-induced

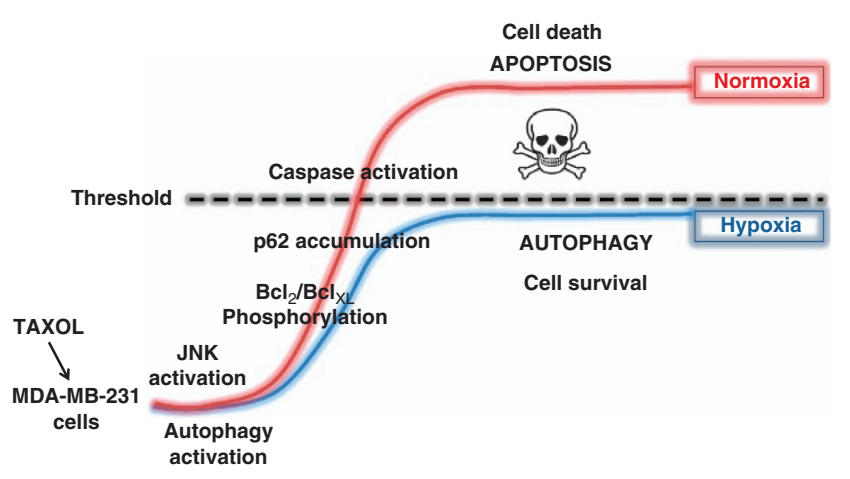

Figure 8 Schematic representation of the lower sensibility of MDA-MB-231 cells against taxol induced cell death under hypoxia. Taxol induces autophagy activation and this activation promotes cell survival against taxol-induced cell death under normoxia and hypoxia. However, under hypoxia autophagy seems to be activated in a more efficient way leading to a more active autophagic flow and solving of the stress, resulting in lower p62 abundance, lower $\mathrm{Bcl}_{2}$ and $\mathrm{Bcl}_{\mathrm{XL}}$ phosphorylation and lower apoptosis activation. In contrast, under normoxia the autophagic flow seems to be saturated, the stress is not properly resolved and exceeds the threshold. P62 accumulation and $\mathrm{BCl}_{2} / \mathrm{Bcl}_{\mathrm{XL}}$ phosphorylation persists, leading to apoptosis activation and cell death

JNK activation promotes cell survival. It could be envisaged that early JNK activation promotes cell survival under normoxia and hypoxia, whereas the sustained JNK activation observed under normoxia can be coupled to prolonged $\mathrm{Bcl}_{2}$ phosphorylation and apoptosis. The connection between JNK activation and autophagy regulation was also studied. No link between JNK activation and autophagy induction after taxol exposure was evidenced, suggesting that JNK is involved in the mechanisms leading to resistance against taxol-induced cell death but not by being involved in autophagy induction. Atg5 and beclin 1 cleavage was also investigated but no cleavage of these proteins was evidenced as being involved in a delayed autophagy inhibition.

In conclusion, taxol induces apoptosis and autophagy activation. Cells incubated under hypoxia are resistant against taxol-induced apoptosis. Autophagy, which is activated earlier than apoptosis, promotes cell survival against taxol-induced cell death under normoxia and hypoxia. The resistance against taxol-induced cell death under hypoxia can be explained by a more efficient autophagic process; which is activated via the classical pathway, that is, via mTOR inhibition but not by JNK activation. Under normoxia, autophagic degradation is less efficient, leading to autophagy saturation, p62 accumulation, persistence of JNK activation and $\mathrm{Bcl}_{2} / \mathrm{Bcl}_{\mathrm{XL}}$ phosphorylation. The intracellular stress induced by taxol exceeds a certain threshold, leading to apoptosis activation and cell death (Figure 8).

\section{Materials and Methods}

Cell culture and hypoxia incubation. Human breast cancer cells MDAMB-231 were maintained in culture in $75 \mathrm{~cm}^{2}$ polystyrene flasks (Costar, Lowell, MA, USA) with $15 \mathrm{ml}$ of Roswell Park Memorial Institute medium (RPMI 1640 Invitrogen, Carlsbad, CA, USA; cat. no. 21875) containing $10 \%$ of fetal calf serum (Invitrogen, cat. no. 10270) and incubated under an atmosphere containing $5 \% \mathrm{CO}_{2}$.

For hypoxia experiments $\left(\begin{array}{lll}1 \% & \mathrm{O}_{2}\end{array}\right)$, cells were incubated in serum-free $\mathrm{CO}_{2}$-independent medium (Invitrogen, cat. no. 18045) supplemented with $1 \mathrm{mM}$ L-glutamine (Sigma, St. Louis, USA; cat. no. G3126) with or without paclitaxel 
(Molecular Probes, Carlsbad, CA, USA; cat. no. P3456) at $50 \mu \mathrm{M}$. Normoxic control cells were incubated in the same conditions but in normal atmosphere $\left(20 \% \mathrm{O}_{2}\right)$.

For some experiments, bafilomycin A1 (100 nM; Sigma, cat. no. B1793), rapamycin (100 nM; Sigma, cat. no. R8781), pepstatin A (10 $\mu \mathrm{g} / \mathrm{ml}$; Sigma, cat. no. P4265), E64D (10 $\mu \mathrm{g} / \mathrm{ml}$; Sigma, cat. no. E8640) or actinomycin D (5 $\mu \mathrm{g} / \mathrm{ml}$; Sigma, cat. no. A9415) were added to the medium.

Caspase 3 activity assay. The fluorogenic substrate Ac-DEVD-AFC was used to measure caspase 3 activity according to Lozano et al. ${ }^{59}$ Cell extracts were prepared as described by Wellington et al. ${ }^{60}$ Cells were seeded in $25 \mathrm{~cm}^{2}$ polystyrene flasks (Costar; 800000 cells/well) 1 day before the incubation. After the incubation, the medium was recovered and centrifuged at $1000 \times g$ for $5 \mathrm{~min}$ Cells still attached to the well were scrapped in $500 \mu \mathrm{l}$ cold PBS and recovered into a microtube. Pelleted detached cells were resuspended in $100 \mu \mathrm{l} \mathrm{PBS}$ at $4{ }^{\circ} \mathrm{C}$ and also added to the microtube. The samples were centrifuged at $1000 \times g$ for $5 \mathrm{~min}$ at $4{ }^{\circ} \mathrm{C}$ and the pellet resuspended in $50 \mu$ of lysis buffer (10 mM Hepes/ $\mathrm{KOH}$ (pH 7.0), 10\% sucrose, $2 \mathrm{mM}$ EDTA, 0.1\% CHAPS, $5 \mathrm{mM}$ dithiothreitol and $10 \mu \mathrm{g} / \mathrm{ml}$ aprotinin). After incubation at $4{ }^{\circ} \mathrm{C}$ on a rotating wheel for $15 \mathrm{~min}$, the lysates were centrifuged at $13000 \times \mathrm{g}$ for $5 \mathrm{~min}$ at $4^{\circ} \mathrm{C}$ and the supernatants were recovered for the assay.

The protein concentration was measured and $10 \mu \mathrm{g}$ proteins completed to $50 \mu$ with lysis buffer were mixed with $13 \mu \mathrm{M}$ Ac-DEVD-AFC (BD Pharmingen, Franklin Lakes, NJ, USA; cat. no. 556574) and $50 \mu$ reaction buffer (40 mM PIPES (pH 7.2), $200 \mathrm{mM} \mathrm{NaCl}, 2 \mathrm{mM}$ EDTA, $0.2 \%$ CHAPS, $0.10 \%$ sucrose and $10 \mathrm{mM}$ dithiothreitol). The reaction was allowed to take place for $1 \mathrm{~h}$ at $37^{\circ} \mathrm{C}$ and the fluorescence generated by the release of the fluorogenic group AFC on cleavage by caspase 3 was measured by excitation at $400 \mathrm{~nm}$ and emission at $505 \mathrm{~nm}$.

LDH release assay. LDH release was measured with the cytotoxicity detection kit from Roche Molecular Biochemicals (Basel, Switzerland) according to the manufacturer's protocol. Cells were seeded in six-well plates (200 000 cells/ well) 1 day before the incubation. The culture media from incubated cells were removed and centrifuged to pellet the cell fragments and apoptotic bodies. In order to lyse the cells, Triton X-100 (Merck, Billerica, MA, USA) at 10\% in PBS was added on this pellet, as well as on the cells remaining in the wells. The percentage $\mathrm{LDH}$ release was calculated as follows:

LDH activity in medium (1) + LDH activity of cell fragments (2)/(1) + (2) + LDH activity of cells remaining in the wells.

Immunofluorescence labeling and confocal microscopy. MDAMB-231 cells were seeded at 30000 cells/well in 24-well plates containing a coverslip, $24 \mathrm{~h}$ before incubation. Cells were incubated for $16 \mathrm{~h}$ with or without taxol under normoxic or hypoxic conditions. After incubation, cells were fixed and permeabilized 10 min with a cold solution of $80 \%$ methanol and $20 \%$ acetone, washed three times with $2 \%$ PBS-BSA and incubated for $2 \mathrm{~h}$ with primary antibodies. Primary antibody for LC3 staining was rabbit anti-LC3 (Sigma, cat. no. L7543; 1/250 dilution) and primary antibody for LAMP1 staining was mouse antiLAMP1 ( $\mathrm{H}_{4} \mathrm{~A}_{3}$-c Developmental Studies Hybridoma Bank; 1/250 dilution). Cells were washed three times with $2 \%$ PBS-BSA and then incubated for $1 \mathrm{~h}$ with secondary antibodies. Alexa Fluor-488-conjugated anti-rabbit IgG antibody (Molecular Probes) was used at 1/1000 dilution and Alexa Fluor-546-conjugated anti-mouse IgG antibody (Molecular Probes) was used at 1/1000 dilution. Cells were then washed three times with PBS, the coverslips were mounted in Mowiol (Sigma) and observed with a confocal microscope.

Western blotting. Cells, seeded and incubated in $25 \mathrm{~cm}^{2}$ flasks, were scrapped in $200 \mu$ of lysis buffer (Tris $40 \mathrm{mM}$ (pH 7.5), KCl $150 \mathrm{mM}$, EDTA $1 \mathrm{mM}$, Triton X-100 1\%) or phospho-protein-specific lysis buffer (Tris HCl $25 \mathrm{mM}(\mathrm{pH} 7.4)$, $\mathrm{NaCl} 150 \mathrm{mM}$, EDTA $1 \mathrm{mM}$, NP 1\%, glycerol 5\%) containing a protease inhibitor mixture («Complete» from Roche Molecular Biochemicals, one tablet in $2 \mathrm{ml} \mathrm{H}_{2} \mathrm{O}$, added at a $1 / 25$ dilution) and phosphatase inhibitors $\left(\mathrm{NaVO}_{3} 25 \mathrm{mM}\right.$, p-nitrophenyl phosphate $250 \mathrm{mM}, \beta$-glycerophosphate $250 \mathrm{mM}$ and $\mathrm{NaF} 125 \mathrm{mM}$, at a $1 / 25$ dilution). Cell lysate was recovered and centrifuged for $5 \mathrm{~min}$ at 13000 r.p.m. at $4{ }^{\circ} \mathrm{C}$ to pellet the cell debris. The supernatant was collected for protein assay and western blot analysis. A measure of 15 or $20 \mu \mathrm{g}$ of proteins were loaded on a NuPage $4-12 \%$ (Invitrogen) for cleaved caspase 3 or on 12\% SDS-PAGE for the other proteins. After migration, proteins were transferred onto a low fluorescence background polyvinylidene fluoride membrane (Millipore, Billerica, MA, USA) at $1 \mathrm{~mA} / \mathrm{cm}^{2}$ during $2 \mathrm{~h}$. Membranes were blocked with Odyssey blocking buffer (BD
Biosciences, Franklin Lakes, NJ, USA) diluted $2 \times$ in PBS for $1 \mathrm{~h}$ at RT. Primary antibodies diluted in Odyssey blocking buffer $0,1 \%$ Tween (Sigma) were incubated O.N. at $4{ }^{\circ} \mathrm{C}$ with membranes washed four times with PBS-Tween $0,1 \%$ and then incubated with secondary antibodies for $1 \mathrm{~h}$ at RT. Membranes were washed four times with PBS-Tween 0,1\%, twice with PBS and then dried $1 \mathrm{~h}$ at $37^{\circ} \mathrm{C}$, and revealed in the Odyssey Licor. Primary antibodies are mouse antiPARP-1 monoclonal antibody (BD Pharmingen, cat. no. 556493), rabbit anti Atg7 polyclonal antibody (Cell Signaling, Danvers, MA, USA; cat. no. 2631), rabbit antiAtg5 antibody (Cell Signaling, cat. no. 2630), mouse anti-LC3 antibody (0231-100/ LC3-5F10 from Nanotools, Munich, Germany), rabbit anti-caspase 3 antibody (Cell Signaling, cat. no. 9662m ), rabbit anti-c-jun antibody (cat. no. 9165 from Cell Signaling), mouse anti-Bcl $\times$ antibody (Sigma, cat. no. B9429), rabbit anti-Bcl antibody (Cell Signaling, cat. no. 2870), rabbit anti-phospho-c-jun antibody (Cell Signaling, cat. no. 9261), rabbit anti-phospho-Bcl 2 monoclonal antibody (Cell Signaling, cat. no. 2827), rabbit anti-phospho-BclxL polyclonal antibody (Millipore, cat. no. AB3116), mouse anti-p62/SQSTM1 antibody (H00008878-M03 from Abnova, Tapei, Taiwan), rabbit anti-phospho-p70S6K antibody (Cell Signaling, cat. no. 9205from), rabbit anti-p70S6K antibody (Cell Signaling, cat. no. 9202), rabbit anti-phospho-mTOR antibody (Cell Signaling, cat. no. 2971), rabbit anti-mTOR antibody (Cell Signaling, cat. no. 2972), rabbit anti-Atg5 antibody (NB110-53818 from Novus Biological, Littleton, CO, USA), mouse anti-Beclin 1 antibody (BD Transduction Laboratories, Franklin Lakes, NJ, USA; cat. no. 612112), mouse anti-Bnip3 antibody (MAB4147 from R\&D Systems, Minneapolis, MN, USA), rabbit anti-Bnip3L antibody (ab8399 from Abcam, Cambridge, UK). Mouse anti- $\beta$-actin antibody (Sigma, cat. no. A5441) and rabbit anti-TOM40 antibody (Santa Cruz Technologies, Dallas, TX, USA; cat. no. 11414) were used for normalization. IRDye $800 \mathrm{CW}$-conjugated goat anti-rabbit antibody $(\mathrm{H}+\mathrm{L}$; Licor, Lincoln, $\mathrm{NE}$, USA; cat. no. 926-32211), IRDye $800 \mathrm{CW}$-conjugated goat anti-mouse antibody $(\mathrm{H}+\mathrm{L}$; Licor, cat. no. 926-32210), IRDye 680LT-conjugated goat anti-rabbit antibody (H+L; Licor, cat. no. 926-68021) and IRDye 680LT-conjugated goat anti-mouse antibody ( $\mathrm{H}+\mathrm{L}$; Licor, cat. no. 926-68020) were used at 1/10000 dilution as secondary antibodies. Quantitative analysis of fluorescence intensity was measured using the Odyssey Classic Infrared Imaging System (Licor).

Real time RT-PCR. After the incubation, total RNA was extracted according to the manufacturer's protocol using the QIAcube (Qiagen, Hilden, Germany). mRNA contained in $2 \mu \mathrm{g}$ total RNA was reverse transcribed using SuperScript II Reverse Transcriptase (Invitrogen) and oligodT primers according to the manufacturer's instructions. Forward and reverse primers for RPL13A and p62 were designed using the Primer Express 1.5 software (Applied Biosystems, Carlsbad, CA, USA). Amplification reaction assays contained $1 \times$ SYBR Green PCR Faststart universal (Roche, Basel, Switzerland) and primers (Applied Biosystems) at the optimal concentrations. A hot start at $95^{\circ} \mathrm{C}$ for 5 min was followed by 40 cycles at $95^{\circ} \mathrm{C}$ for $15 \mathrm{~s}$ and $65^{\circ} \mathrm{C}$ for 1 min using an $\mathrm{ABI}$ PRISM 7000 SDS thermal cycler (Applied Biosystems). RPL13A was used as the reference gene for normalization and mRNA expression level was quantified using the threshold cycle method.

siRNA transfection. Silencing of Atg7, Atg5, JNK1 and JNK2 and p62 expression was achieved using ON-TARGET plus SMARTpool human Atg7 (Dharmacon, Lafayette, CO, USA; cat. no. L020112), SMARTpool siGENOME human Atg5 (Dharmacon, cat. no. M00437404), ON-TARGET plus SMARTpool human MAPK8 (JNK1; Dharmacon, cat. no. L003514) and ON-TARGET plus SMARTpool human MAPK9 (JNK2; Dharmacon, cat. no. L003505), ON-TARGET plus SMARTpool human SQSTM1 (p62; Dharmacon, cat no. L010230). RF control siRNA purchased from Dharmacon was used to control for non-specific effects. For siRNA experiments, $8 \times 10^{5}$ cells were seeded in $25 \mathrm{~cm}^{2}$ polystyrene flasks (Costar) with $4 \mathrm{ml}$ of RPMl 1640 medium containing $10 \%$ of fetal calf serum and incubated for $24 \mathrm{~h}$ under an atmosphere containing $5 \% \mathrm{CO}_{2}$. Cells were then transfected for $24 \mathrm{~h}$ under standard culture conditions with $50 \mathrm{nM}$ siRNA using the DharmaFECT 1 (Dharmacon) transfection reagent according to the manufacturer's instructions. The transfection media were removed and replaced by culture media for $24 \mathrm{~h}$. Cells were then incubated as previously described.

DQ-Green-BSA proteolysis assay. Lysosomal-dependent proteolysis was visualized by the use of self-quenched Bodipy dye conjugates of BSA (DQ-BSA, D-12050 from Molecular Probes). Cells were plated in Lab-tek (for confocal microscopy) or in six-well plate (for flow cytometry), $24 \mathrm{~h}$ before the incubation. Cells were incubated under normoxia or hypoxia with or without taxol 
and/or bafilomycin A. DQ-Green-BSA dye was added to each well at a concentration of $50 \mu \mathrm{g} / \mathrm{ml}$. A well without DQ-Green-BSA served as a negative control. After the incubation, lysotracker red were added at a concentration of $100 \mathrm{nM}$ for $20 \mathrm{~min}$ before imaging with confocal microscopy or cells were harvested and analyzed by flow cytometry.

Flow cytometry. After the incubation, cells were rinsed with PBS, trypsinized and rinsed with PBS again. Cells were analyzed by flow cytometry with a FACScalibur (BD Biosciences), using FL1-H channel for DQ-Green-BSA fluorescence. The median was calculated for each condition using the Cell Quest Pro software. Results are expressed as median value for each condition.

\section{Conflict of Interest}

The authors declare no conflict of interest.

Acknowledgements. Annick Notte is a Research Fellow at FNRS (Fonds de la Recherche Scientifique, Belgium). The LAMP1 monoclonal antibody was obtained from the Developmental Studies Hybridomas Bank developed under the auspices of the NICHD and maintained by the Department of Biology, University of lowa.

1. Brahimi-Horn MC, Chiche J, Pouyssegur J. Hypoxia and cancer. J Mol Med 2007; 85: 1301-1307.

2. Fukumura D, Jain RK. Tumor microenvironment abnormalities: causes, consequences, and strategies to normalize. J Cell Biochem 2007; 101: 937-949.

3. Vaupel P, Kelleher DK, Hockel M. Oxygen status of malignant tumors: pathogenesis of hypoxia and significance for tumor therapy. Semin Oncol 2001; 28(Suppl 8): 29-35.

4. Cosse JP, Michiels C. Tumour hypoxia affects the responsiveness of cancer cells to chemotherapy and promotes cancer progression. Anticancer Agents Med Chem 2008; 8: 790-797.

5. White E, DiPaola RS. The double-edged sword of autophagy modulation in cancer. Clin Cancer Res 2009; 15: 5308-5316.

6. Apel A, Zentgraf H, Buchler MW, Herr I. Autophagy-A double-edged sword in oncology. Int J Cancer 2009; 125: 991-995.

7. Bialik S, Kimchi A. Autophagy and tumor suppression: recent advances in understanding the link between autophagic cell death pathways and tumor development. Adv Exp Med Biol 2008; 615: 177-200.

8. Brech A, Ahlquist T, Lothe RA, Stenmark H. Autophagy in tumour suppression and promotion. Mol Oncol 2009; 3: 366-375.

9. Degenhardt K, Mathew R, Beaudoin B, Bray K, Anderson D, Chen G et al. Autophagy promotes tumor cell survival and restricts necrosis, inflammation, and tumorigenesis. Cancer cell 2006; 10: 51-64.

10. Boya P, Gonzalez-Polo RA, Casares N, Perfettini JL, Dessen P, Larochette N et al. Inhibition of macroautophagy triggers apoptosis. Mol Cell Biol 2005; 25: 1025-1040.

11. Checinska A, Soengas MS. The gluttonous side of malignant melanoma: basic and clinical implications of macroautophagy. Pigment Cell Melanoma Res 2011; 24: 1116-1132.

12. Notte A, Leclere L, Michiels C. Autophagy as a mediator of chemotherapy-induced cell death in cancer. Biochem Pharmacol 2011; 82: 427-434.

13. Codogno P, Meijer AJ. Autophagy and signaling: their role in cell survival and cell death. Cell Death Differ 2005; 12(Suppl 2): 1509-1518.

14. Shen S, Kepp O, Kroemer G. The end of autophagic cell death? Autophagy 2012; 8: 1-3.

15. Mazure NM, Pouyssegur J. Hypoxia-induced autophagy: cell death or cell survival? Curr Opin Cell Biol 2010; 22: 177-180.

16. Zhang H, Bosch-Marce M, Shimoda LA, Tan YS, Baek JH, Wesley JB et al. Mitochondrial autophagy is an HIF-1-dependent adaptive metabolic response to hypoxia. J Biol Chem 2008; 283: 10892-10903.

17. Song J, Qu Z, Guo X, Zhao Q, Zhao X, Gao L et al. Hypoxia-induced autophagy contributes to the chemoresistance of hepatocellular carcinoma cells. Autophagy 2009; 5: 1131-1144.

18. Rouschop KM, van den Beucken T, Dubois L, Niessen H, Bussink J, Savelkouls K et al. The unfolded protein response protects human tumor cells during hypoxia through regulation of the autophagy genes MAP1LC3B and ATG5. J Clin Invest 2010; 120: 127-141.

19. Papandreou I, Lim AL, Laderoute K, Denko NC. Hypoxia signals autophagy in tumor cells via AMPK activity, independent of HIF-1, BNIP3, and BNIP3L. Cell Death Differ 2008; 15 : 1572-1581.

20. Maiuri MC, Zalckvar E, Kimchi A, Kroemer G. Self-eating and self-killing: crosstalk between autophagy and apoptosis. Nat Rev Mol Cell Biol 2007; 8: 741-752.

21. Eisenberg-Lerner A, Bialik S, Simon HU, Kimchi A. Life and death partners: apoptosis, autophagy and the cross-talk between them. Cell Death Differ 2009; 16: 966-975.

22. Liang XH, Kleeman LK, Jiang HH, Gordon G, Goldman JE, Berry G et al. Protection against fatal Sindbis virus encephalitis by beclin, a novel Bcl-2-interacting protein. J Virol 1998; 72 : 8586-8596.
23. Fimia GM, Piacentini M. Regulation of autophagy in mammals and its interplay with apoptosis. Cell Mol Life Sci 2010; 67: 1581-1588.

24. Wei Y, Pattingre S, Sinha S, Bassik M, Levine B. JNK1-mediated phosphorylation of Bcl-2 regulates starvation-induced autophagy. Mol Cell 2008; 30: 678-688.

25. Zhou F, Yang Y, Xing D. Bcl-2 and Bcl-xL play important roles in the crosstalk between autophagy and apoptosis. FEBS J 2011; 278: 403-413.

26. Wiseman LR, Spencer CM. Paclitaxel. An update of its use in the treatment of metastatic breast cancer and ovarian and other gynaecological cancers. Drugs Aging 1998; 12 : 305-334.

27. Cosse JP, Sermeus A, Vannuvel K, Ninane N, Raes M, Michiels C. Differential effects of hypoxia on etoposide-induced apoptosis according to the cancer cell lines. Mol Cancer 2007; 6: 61.

28. Piret JP, Cosse JP, Ninane N, Raes M, Michiels C. Hypoxia protects HepG2 cells against etoposide-induced apoptosis via a HIF-1-independent pathway. Exp Cell Res 2006; 312: 2908-2920.

29. Sermeus A, Cosse JP, Crespin M, Mainfroid V, de Longueville F, Ninane N et al. Hypoxia induces protection against etoposide-induced apoptosis: molecular profiling of changes in gene expression and transcription factor activity. Mol Cancer 2008; 7: 27.

30. Flamant L, Notte A, Ninane N, Raes M, Michiels C. Anti-apoptotic role of HIF-1 and AP-1 in paclitaxel exposed breast cancer cells under hypoxia. Mol Cancer 2010; 9: 191.

31. Wouters BG, Koritzinsky M. Hypoxia signalling through mTOR and the unfolded protein response in cancer. Nat Rev Cancer 2008; 8(11): 851-864.

32. Cosse JP, Rommelaere G, Ninane N, Arnould T, Michiels C. BNIP3 protects HepG2 cells against etoposide-induced cell death under hypoxia by an autophagy-independent pathway. Biochem Pharmacol 2010; 80: 1160-1169.

33. Xi G, Hu X, Wu B, Jiang H, Young CY, Pang Y et al. Autophagy inhibition promotes paclitaxel-induced apoptosis in cancer cells. Cancer Lett 2011; 307: 141-148.

34. Ichimura $\mathrm{Y}$, Komatsu M. Selective degradation of p62 by autophagy. Seml Immunopathol 2010; 32: 431-436.

35. Fass E, Shvets E, Degani I, Hirschberg K, Elazar Z. Microtubules support production of starvation-induced autophagosomes but not their targeting and fusion with lysosomes. J Biol Chem 2006; 281: 36303-36316.

36. Jahreiss L, Menzies FM, Rubinsztein DC. The itinerary of autophagosomes: from peripheral formation to kiss-and-run fusion with lysosomes. Traffic 2008; 9: 574-587.

37. Kochl R, Hu XW, Chan EY, Tooze SA. Microtubules facilitate autophagosome formation and fusion of autophagosomes with endosomes. Traffic 2006; 7: 129-145.

38. Bellot G, Garcia-Medina R, Gounon P, Chiche J, Roux D, Pouyssegur J et al. Hypoxiainduced autophagy is mediated through hypoxia-inducible factor induction of BNIP3 and BNIP3L via their BH3 domains. Mol Cell Biol 2009; 29: 2570-2581.

39. Strasser A, Puthalakath H, Bouillet P, Huang DC, O'Connor L, O'Reilly LA et al. The role of bim, a proapoptotic BH3-only member of the Bcl-2 family in cell-death control. AnnN Y Acad Sci 2000; 917: 541-548.

40. Wang TH, Wang HS, Ichijo H, Giannakakou P, Foster JS, Fojo T et al. Microtubuleinterfering agents activate $\mathrm{c}$-Jun $\mathrm{N}$-terminal kinase/stress-activated protein kinase through both Ras and apoptosis signal-regulating kinase pathways. J Biol Chem 1998; 273: 4928-4936.

41. Lee LF, Li G, Templeton DJ, Ting JP. Paclitaxel (Taxol)-induced gene expression and cell death are both mediated by the activation of c-Jun NH2-terminal kinase (JNK/SAPK). J Biol Chem 1998; 273: 28253-28260.

42. Weston CR, Davis RJ. The JNK signal transduction pathway. Curr Opin Cell Biol 2007; 19: $142-149$.

43. Raciti M, Lotti LV, Valia S, Pulcinelli FM, Di Renzo L. JNK2 is activated during ER stress and promotes cell survival. Cell Death Disease 2012; 3: e429.

44. Wirawan E, Vande Walle L, Kersse K, Cornelis S, Claerhout S, Vanoverberghe I et al. Caspase-mediated cleavage of Beclin-1 inactivates Beclin-1-induced autophagy and enhances apoptosis by promoting the release of proapoptotic factors from mitochondria. Cell Death Disease 2010; 1: e18.

45. Yousefi S, Perozzo R, Schmid I, Ziemiecki A, Schaffner T, Scapozza L et al. Calpainmediated cleavage of Atg5 switches autophagy to apoptosis. Nature Cell Biol 2006; 8: 1124-1132.

46. Verspurten J, Gevaert K, Declercq W, Vandenabeele P. SitePredicting the cleavage of proteinase substrates. Trends Biochem Sci 2009; 34: 319-323.

47. Kroemer G, Marino G, Levine B. Autophagy and the integrated stress response. Mol Cell 2010; 40: 280-293.

48. Veldhoen RA, Banman SL, Hemmerling DR, Odsen R, Simmen T, Simmonds AJ et al. The chemotherapeutic agent paclitaxel inhibits autophagy through two distinct mechanisms that regulate apoptosis. Oncogene 2013; 32: 736-746.

49. Arstila AU, Nuuja IJ, Trump BF. Studies on cellular autophagocytosis. Vinblastine-induced autophagy in the rat liver. Exp Cell Res 1974; 87: 249-252.

50. Marzella L, Sandberg PO, Glaumann H. Autophagic degradation in rat liver after vinblastine treatment. Exp Cell Res 1980; 128: 291-301.

51. Pursiheimo JP, Rantanen K, Heikkinen PT, Johansen T, Jaakkola PM. Hypoxiaactivated autophagy accelerates degradation of SQSTM1/p62. Oncogene 2009; 28: 334-344.

52. Spugnini EP, Citro G, Fais S. Proton pump inhibitors as anti vacuolar-ATPases drugs: a novel anticancer strategy. J Exp Clin Cancer Res 2010; 29: 44. 
53. Pattingre S, Tassa A, Qu X, Garuti R, Liang XH, Mizushima N et al. Bcl-2 antiapoptotic proteins inhibit Beclin 1-dependent autophagy. Cell 2005; 122: 927-939.

54. Liu J, Lin A. Role of JNK activation in apoptosis: a double-edged sword. Cell Research 2005; 15: 36-42.

55. Wang TH, Wang HS, Soong YK. Paclitaxel-induced cell death: where the cell cycle and apoptosis come together. Cancer 2000; 88: 2619-2628.

56. Ruvolo PP, Deng X, May WS. Phosphorylation of Bcl2 and regulation of apoptosis. Leukemia 2001; 15: 515-522.

57. Deng X, Gao F, May WS Jr.. Bcl2 retards G1/S cell cycle transition by regulating intracellular ROS. Blood 2003; 102: 3179-3185.

58. Ventura JJ, Hubner A, Zhang C, Flavell RA, Shokat KM, Davis RJ. Chemical genetic analysis of the time course of signal transduction by JNK. Mol Cell 2006; 21: 701-710.

59. Lozano J, Menendez S, Morales A, Ehleiter D, Liao WC, Wagman R et al. Cell autonomous apoptosis defects in acid sphingomyelinase knockout fibroblasts. J Biol Chem 2001; 276: $442-448$.
60. Wellington CL, Ellerby LM, Hackam AS, Margolis RL, Trifiro MA, Singaraja R et al. Caspase cleavage of gene products associated with triplet expansion disorders generates truncated fragments containing the polyglutamine tract. J Biol Chem 1998; 273: 9158-9167.

Cell Death and Disease is an open-access journal published by Nature Publishing Group. This work is licensed under a Creative Commons Attribution-NonCommercialNoDerivs 3.0 Unported License. To view a copy of this license, visit http://creativecommons.org/licenses/by-nc-nd/3.0/

Supplementary Information accompanies this paper on Cell Death and Disease website (http://www.nature.com/cddis) 